\title{
Erratum to: Long-term clinical outcome of the symmetry aortic connector system in off-pump coronary artery bypass grafting. Thorac Cardiovasc Surg 2013;61(8):669-675
}

Niels J. Verberkmoes ${ }^{1} \quad$ M. Mostafa Mokhles ${ }^{2}$ Sander Bramer ${ }^{1} \quad$ Albert H.M. van Straten ${ }^{1}$ Joost F. ter Woorst ${ }^{1}$ Jos G. Maessen ${ }^{3}$ Eric Berreklouw ${ }^{1}$

${ }^{1}$ Department of Cardiothoracic Surgery, Catharina Hospital, Eindhoven, The Netherlands

2 Department of Cardiothoracic Surgery, Erasmus Medical Center, Rotterdam, The Netherlands

${ }^{3}$ Department of Cardiothoracic Surgery, Cardiovascular Research Institute Maastricht-CARIM, Maastricht University Medical CenterMUMC, Maastricht, The Netherlands

Thorac Cardiovasc Surg 2014;62:196.

Address for correspondence Niels J. Verberkmoes, MD, Department of Cardiothoracic Surgery, Catharina Hospital Eindhoven, Michelangelolaan 2, 5623 EJ Eindhoven, The Netherlands (e-mail: niels.verberkmoes@catharina-ziekenhuis.nl).

\section{ERRATUM}

It has been brought to the Publisher's attention that the author name "M. Mostafa Mokhles" is not appearing correctly in the abovementioned article, published eFirst on June 8, 2012. DOI of the original article is DOI: $10.1055 / \mathrm{s}-0032-1311539$.

The name should be read as "Mokhles, M. Mostafa" in place of "Mostafa Mokhles, M." 